Review

\title{
Conventional and Non-Conventional Yeasts in Beer Production
}

\author{
Angela Capece *, Rossana Romaniello, Gabriella Siesto and Patrizia Romano \\ Scuola di Scienze Agrarie, Forestali, Alimentari ed Ambientali, Università degli Studi della Basilicata, \\ Viale Ateneo Lucano, 10-85100 Potenza, Italy; rossanaromaniello@yahoo.it (R.R.); gasiesto1@virgilio.it (G.S.); \\ patrizia.romano@unibas.it (P.R.) \\ * Correspondence: angela.capece@unibas.it; Tel.: +39-097-1205686
}

Received: 4 May 2018; Accepted: 30 May 2018; Published: 1 June 2018

\begin{abstract}
The quality of beer relies on the activity of fermenting yeasts, not only for their good fermentation yield-efficiency, but also for their influence on beer aroma, since most of the aromatic compounds are intermediate metabolites and by-products of yeast metabolism. Beer production is a traditional process, in which Saccharomyces is the sole microbial component, and any deviation is considered a flaw. However, nowadays the brewing sector is faced with an increasing demand for innovative products, and it is diffusing the use of uncharacterized autochthonous starter cultures, spontaneous fermentation, or non-Saccharomyces starters, which leads to the production of distinctive and unusual products. Attempts to obtain products with more complex sensory characteristics have led one to prospect for non-conventional yeasts, i.e., non-Saccharomyces yeasts. These generally are characterized by low fermentation yields and are more sensitive to ethanol stress, but they provide a distinctive aroma and flavor. Furthermore, non-conventional yeasts can be used for the production of low-alcohol/non-alcoholic and light beers. This review aims to present the main findings about the role of traditional and non-conventional yeasts in brewing, demonstrating the wide choice of available yeasts, which represents a new biotechnological approach with which to target the characteristics of beer and to produce different or even totally new beer styles.
\end{abstract}

Keywords: Saccharomyces brewing yeasts; non-conventional yeasts; beer; bioflavoring; low-alcohol beers; light beers; innovative beer styles

\section{Introduction}

The mostly used brewer's yeast belongs to the genus Saccharomyces, in consequence of some characteristics essential for the brewing process, such as the production of a high level of ethanol with high efficiency, the metabolism of sugars preferentially using the fermentative pathway based on the presence of the Crabtree effect (repression of respiration by glucose) and its ability to tolerate numerous environmental stresses (firstly, the ethanol presence [1]).The quality of any beer is, in large part, determined by the yeast strain employed and yeast management in fermentations is also a critical brewing parameter. This review summarizes current knowledge on the influence of traditional and non-conventional yeasts on beer characteristics and the potentiality of new yeasts for the production of innovative beers.

\section{Spontaneous Fermentations}

The spontaneous fermentation processes are driven by brewery-resident microorganisms. The best-known spontaneous fermentation beers are the Lambics of Belgium and (to a lesser extent) their offspring, the "coolship ales" of the United States, an American descendant of the Belgian Lambic style. The production of Lambic beer is based on uncontrolled fermentative process, performed 
by microorganisms resident in breweries that contaminate the wort during the overnight cooling performed in thin tanks, after which the wort is moved in wooden barrels, in which it is submitted to fermentation and aging. Several yeasts and bacterial species develop during the fermentative process, although it was identified a microbial consortium regularly present in different fermentation batches, indicating that in each brewhouse a resident microbiota is present, which allows one to increase process reproducibility among successive fermentations. Furthermore, the core profile of the American coolship ale fermentation displayed some remarkable similarities to the microbial profile of Belgian Lambics, suggesting that the shared production methods create a common selective niche environment for spontaneous beer fermentations. These processes generally show three distinct phases: initial phase, main fermentation, and maturation. The first phase of the fermentation is characterized by a broad microbial diversity mainly consisting of Enterobacteria, including Klebsiella, Enterobacter, Escherichia, Citrobacter, Serratia, and Pectobacterium and non-Saccharomyces yeasts, primarily Kluyveromyces in lambic and Rhodotorula in coolship ale [2]. Different compounds responsible for aroma characteristic of lambic aged for 1-2 months, such as 2,3-butanediol; ethyl acetate; higher alcohols; and acetic, lactic, and succinic acids, are produced by Enterobacteria present during this stage [3]. Subsequently, the change of physical and chemical characteristics of fermenting wort, mainly the increase of ethanol concentration and reduction of $\mathrm{pH}$, favour the Saccharomyces spp, which overcome non-Saccharomyces spp. and perform the main part of alcoholic fermentation, with conversion of most fermentable sugars present in the wort into ethanol. This step proceeds for about $3-4$ months. Lactic acid bacteria (primarily Pediococcus) and (in lower numbers) acetic acid bacteria coexist with these Saccharomyces spp. The number of Saccharomyces cells decreases after consumption of all the sugars fermentable by these species (generally mono-, di-, and trisaccharides, such as glucose, fructose, sucrose, maltose, and maltotriose), which are replaced by Brettanomyces spp., mainly B. bruxellensis, which reaches $10^{4}-10^{5}$ cells $/ \mathrm{mL}$ and remains the dominant microbial subgroup during maturation, which lasts several months or even years. Brettanomyces spp. combine high tolerance to ethanol with the ability to superattenuate the fermenting wort, meaning that they can utilize more complex carbohydrates, such as maltotetraose and maltopentaose, which are normally not fermented (or attenuated) by Saccharomyces spp. Brettanomyces produces a range of aroma compounds, characteristic of lambic, such as caprylic and capric fatty acids and their ethyl esters. Since these beers are fermented and matured in the same vessel sur lies, the unique flavor profile is likely influenced by microbial autolysis.

\section{Traditional Starter Yeasts}

Brewer's yeasts are mostly part of the genus Saccharomyces and can traditionally be divided into two groups: ale and lager yeasts, also known as the top-fermenting and bottom-fermenting yeasts, respectively. Originally, these strains were classified on the basis of their flocculation properties. At the end of fermentation, top yeast tends to rise to the surface of the fermented wort, whereas bottom yeast settles to the bottom of the fermentation vessel. Furthermore, these two types of brewing yeasts are differentiated also on the basis of growth and fermentation temperature. Although the optimum growth temperature for Saccharomyces is between 25 and $30^{\circ} \mathrm{C}$, the growth and fermentation of bottom yeasts are performed between 4 and $12{ }^{\circ} \mathrm{C}$, whereas for top fermenting yeasts temperatures ranging between 14 and $25^{\circ} \mathrm{C}$ are used.

\subsection{Ale Yeasts}

Although ale yeasts are used for the production of beers with very different characteristics among them, such as ale, stout, or porter, the strains used for these beers belong mainly to S. cerevisiae species. Until recently, the phylogenetic relationships of the ale yeast strains used for the different beer styles and their relationships with non-brewing S. cerevisiae strains have been poorly understood. By using microsatellite markers, Legras et al. [4] gave the first indication that wine and ale beer strains were genetically distinct. Gallone et al. [5] and Gonçalves et al. [6] investigated a wide collection 
of ale-type beer yeasts using complete genome sequences and showed that they were distinct from other industrially relevant strains of $S$. cerevisiae. Ale-type strains were grouped in a main cluster that included various types of German, British, Belgian, and American beer strains. However, beer strains were also found to cluster in the wine, bread, and sake clades, as well as in an independent clade sister to the wine clade. However, within S. cerevisiae group, beer strains are more diverse than wine strains, and it was found that in nature many top yeast strains are hybrids. In fact, Gonzalez et al. [7] reported that $25 \%$ of top strains found in Belgian Trappist beers are likely to have been generated by the hybridization between S. cerevisiae and S. kudriavzevii. Those authors also showed that beer yeasts have a high incidence of polyploidy and aneuploidy and, probably as a consequence of this, limited or no sporulation ability. Genome analyses and large-scale phenotyping of industry-specific traits revealed that some traits have been selected during brewing yeast domestication, such as greater capacity to metabolize maltotriose [5] and reduced production of phenolic off flavours.

\subsection{Lager Yeasts}

As regards bottom yeast strains, used for the production of lager beers and now assigned to S. pastorianus, the situation is more complicated than ale yeasts. As lager yeasts are responsible for more than $90 \%$ of the beer produced worldwide, much more attention has been given to them [8]. It has long been known that bottom brewer's yeast strains of S. pastorianus are hybrids, but it was assumed that they were hybrids of S. cerevisiae and S. bayanus [9-12]. However, S. bayanus has very low sequence identity (92.5\%) when compared with the non-S. cerevisiae genome of S. pastorianus. Actually, lager yeasts are classified as allopolyploid hybrids of S. cerevisiae and S. eubayanus [11-13]. A S. eubayanus strain with high identity $(99.5 \%)$ with the non-S. cerevisiae part of the S. pastorianus genome was firstly isolated in Patagonia [13]. The main features of S. eubayanus are cold tolerance and strain cold-tolerance is directly correlated with the proportion of the S. eubayanus genome [14]. The tolerance to high ethanol concentrations of S. eubayanus is lower than the resistance of traditional ethanol producing strains.

The genomes of the individual strains of S. pastorianus are various combinations of genomes of the species S. cerevisiae and S. eubayanus. The lager yeast has been divided long time ago into two groups: (I) Saaz and (II) Frohberg [15]. S. pastorianus group I (Saaz) was produced by hybridization of S. cerevisiae (ale) with S. eubayanus, whereas S. pastorianus group II (Frohberg) was obtained by a further hybridization with a different $S$. cerevisiae strain used in stout production (Figure 1). This indicates that two hybridizations were involved in the obtaining of second group, and for this species two independent origins can be speculated [11,16]. As generally Saaz strains are not able to ferment maltotriose, the growth and fermentative activity of these strains are slower than Frohberg strains [14,17].

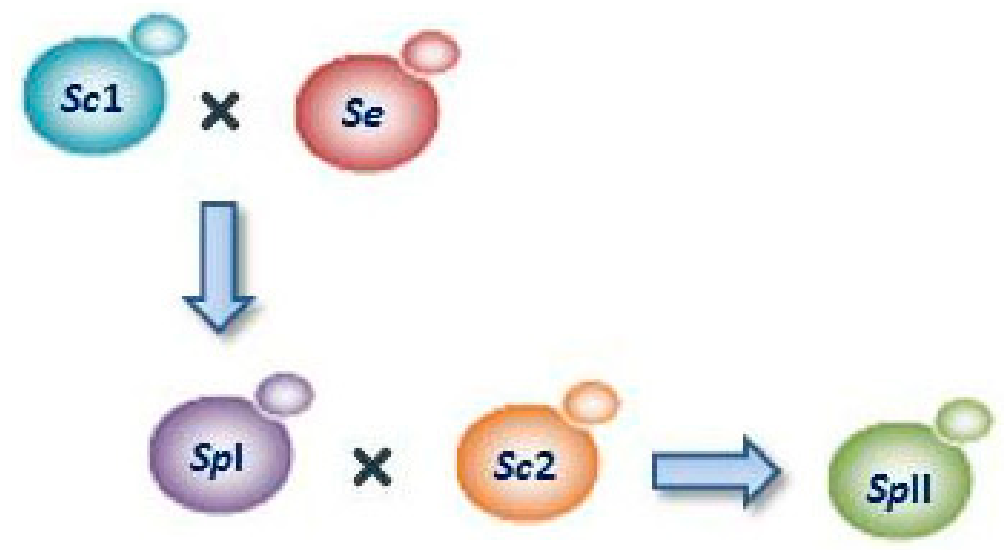

Figure 1. Origin of lager yeasts Saccharomyces pastorianus group I ( $S p \mathrm{I})$ and II (SpII). SpI was produced by hybridization of $S$. cerevisiae ( $S c 1)$ with $S$. eubayanus $(S e)$, and $S p$ II was obtained by a further hybridization between $S p I$ and a different $S$. cerevisiae strain $(S c 2)$. 
Some authors report that the genome of some strains may also contain portion from other yeasts belonging to the Saccharomyces evolutionary group [18]. This affects characteristics and ability of specific strains, whose genotype is influenced by strain origin. Strains with specific properties were correlated with some breweries or a locality, and genetic features, such as genomic arrangement, number of copies, ploidy, and polymorphisms characterize each strain [19]. Sequencing of the genomes of groups I and II lager yeasts confirmed these findings [20-23].

Ale strains are characterized by higher diversity than lager strains; this might be due to their origin; the greater diversity of ale strains reflects their isolation in multiple locations, whereas the lager strains emerged from a very limited locality.

\subsection{Influence of Saccharomyces Yeasts on Beer Flavor}

The production of quality beer relies on the activity of fermenting yeasts that are qualified not only for good fermentation yield-efficiency, but also for affecting aroma and flavor to the beverage [24]. The flavour profiles of beer can principally be attributed to the biochemical activities during fermentation within the yeast cell, in which wort sugars are converted to ethanol and volatile compounds, such as higher alcohols and esters, which are intermediate compounds and by-products of yeast metabolism. These volatile compounds are dissimilar to the aromatic compounds present in malt and hops and have an important impact on the aroma and taste of beer. Ethanol and $\mathrm{CO}_{2}$ are the primary by-products formed during fermentation; other yeast-derived flavour-active compounds are carbonyls (aldehydes/ketones), higher/fusel alcohols, esters, vicinal diketones (diacetyl and pentanedione), fatty and organic acids, and sulphur compounds. The two key nutrient classes that influence brewing yeast performance are carbohydrates and nitrogenous compounds. Brewing strains can use numerous carbohydrates (glucose, sucrose, fructose, maltose, galactose, raffinose, and maltotriose), and the principal characteristic differentiating ale and lager yeasts is the ability of lager yeasts to ferment melibiose. The generalized sugar uptake pattern starts with the uptake of the simplest sugars (glucose and fructose), followed in increasing order of complexity by disaccharides (maltose) and trisaccharides. As regards nitrogen compounds, the main function of the malt is to provide assimilable nitrogen sources to the yeast, which is represented by amino acids, ammonium ion, and some di- and tri-peptides. The greater part of wort-free amino nitrogen (FAN) is utilized by yeast for formation of proteins needed for yeast growth. However, the level and composition of wort FAN has a significant influence on higher alcohol, ester, vicinal diketones, and $\mathrm{H}_{2} \mathrm{~S}$ formation owing to the function of amino acid metabolism in the formation of these flavor compounds.

\section{Non-Conventional Yeasts}

Increasing demand for innovative products, alternative flavours, and low-alcohol beers has stimulated research into the potential benefits of alternative yeasts; in particular, non-Saccharomyces species have been isolated and characterized for the development of specialty beers [25]. Wild and undomesticated non-Saccharomyces yeast strains can provide different aroma and flavour characteristics that result in new beer variations and styles. However, since non-Saccharomyces yeasts represent undomesticated strains, their fermentation characteristics have a greater variation than Saccharomyces yeasts, and they can affect the consistency and quality of the produced beers. Although we have a poor understanding of these characteristics for non-Saccharomyces yeasts, they present many opportunities for brewers. In order to satisfy the expansion of the sector and increasing request by specialized consumers, the brewers introduced a lot of innovation in the production process, such as the use of different hop varieties or special malts and the preparation of particular blends, among others. A natural alternative to help bring innovation to this sector is the use of non-Saccharomyces yeasts, which allow one to find a multiplicity of aroma and flavor products, affecting the overall organoleptic profile of beers. Until now, however, the use of these non-conventional species as alternative yeasts in brewing showed only limited diffusion. Generally, it is assumed that non-Saccharomyces yeasts play a negative role in the brewing process in consequence of problems associated with beer 
turbidity, filterability, viscosity, phenolic off-flavours (POF), sourness, and other flavour profile changes. These organisms have been more enthusiastically introduced in the wine industry, as these yeasts are a normal component of microflora developing during fermentation. Modern breweries maintain high levels of hygiene, and brewers are understandably reluctant to introduce foreign strains that are potentially responsible for contamination. The successful application of non-conventional yeasts in brewing is the handling of these new yeasts in a controlled manner to achieve desired beer characteristics. As non-conventional yeast species generally have a lower performance for ethanol production compared to $S$. cerevisiae, they have only been rarely used as pure starter cultures for the production of alcoholic beverages, whereas they are frequently used during co- or sequential fermentations with $S$. cerevisiae. Furthermore, the use of these yeasts in brewing may, in some cases, require important changes to process conditions, such as oxygen availability. In standard brewing, wort is aerated before or at the time of pitching to support initial growth of the yeast population; after that, fermentation proceeds without additional oxygen. On the contrary, when some non-conventional yeasts are employed (i.e., Torulaspora delbrueckii and Brettanomyces spp.), low level of oxygen is necessary to support fermentation [26,27]. In the case of co-cultivation of Saccharomyces and nonconventional yeasts, this dependence on oxygen may play a positive role in controlling the growth of the latter, thereby ensuring successful completion of fermentation by the former. A further complication is the short list of yeasts that are unequivocally and generally recognized as safe (GRAS/QPS) for use in food production [28], and further testing may be necessary to ensure consumer safety.

This review will discuss the potential to use non-Saccharomyces yeasts to increase the content of specific target flavours in beers (bioflavoring), for the production of low-alcohol/no-alcohol and light beers (Table 1).

Table 1. Role of non-conventional yeasts for production of innovative beers.

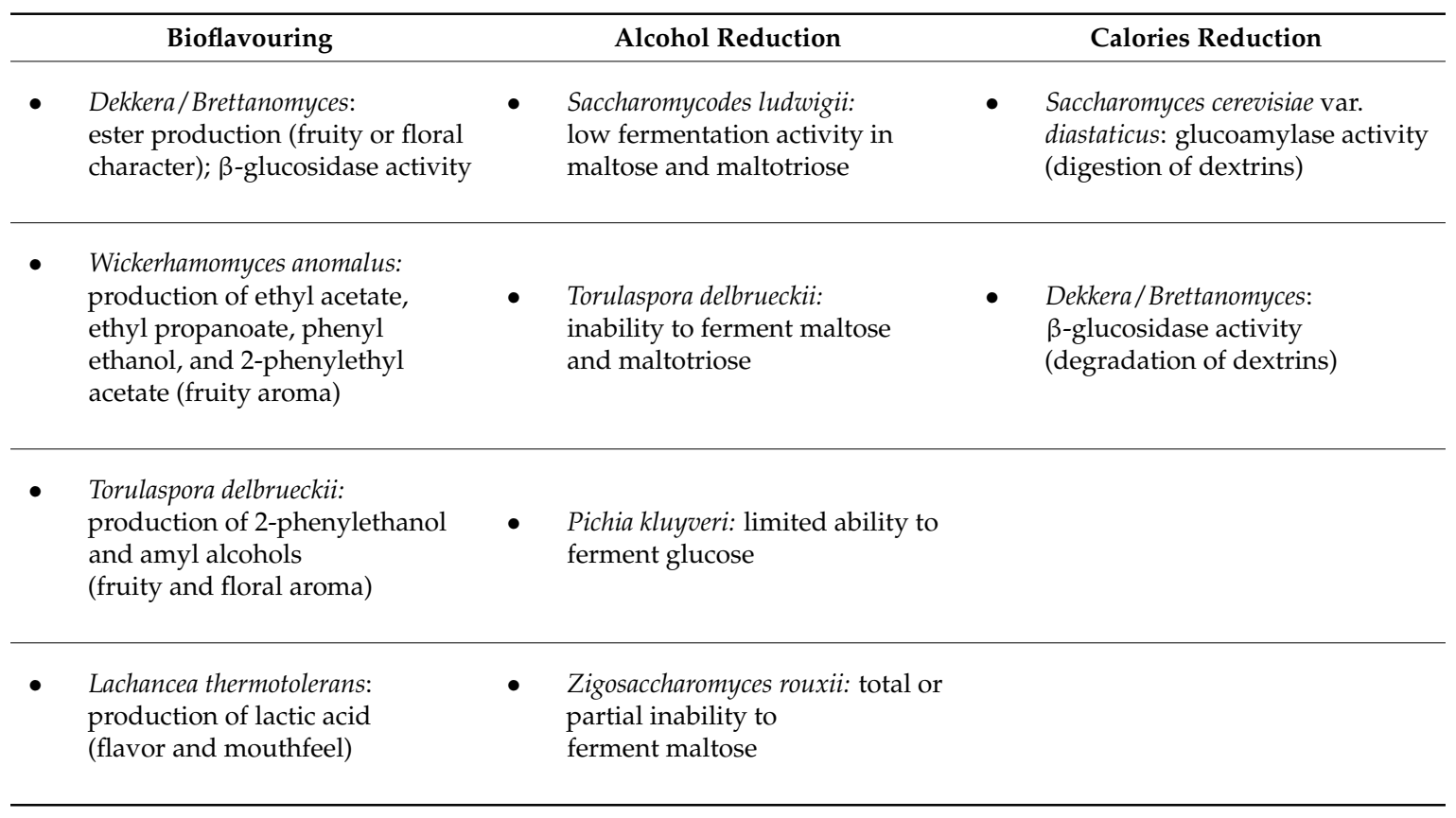

\subsection{Non-Conventional Yeasts for Bioflavoring}

The use of non-conventional yeasts in brewing can satisfy the concept of bioflavoring, which is described as the synthesis and transformation of flavor compounds by biological methods. This approach meets modern consumer expectations, satisfying the consumer research both for beers with enhanced and differentiated sensory profiles and for products without chemical additives. Conferring of new compounds and flavor by biological methods can be achieved by (a) inoculating 
a single yeast species as pure culture; (b) using different microorganisms in sequential or co-inoculated fermentations; (c) use of genetically modified organisms (GMOs); and (d) addition of enzyme secreted by other microorganisms [29]. Controlled use of non-conventional yeasts during wort fermentation may be a viable option to increase the content of specific target flavours in beers.

Dekkera/Brettanomyces species are the most relevant non-conventional yeasts involved in the production of sour beers, mainly in Lambic beers, and have attracted growing interest from brewers and connoisseurs. In recent years, an increasing amount of research has reported the use of these yeasts in controlled fermentations, both in pure cultures and in co-inoculation with S. cerevisiae [1]. Dekkera/Brettanomyces confer very peculiar sensory characteristics to the beverage, mainly in consequence of the production of phenolic off-flavors (POF). Otherwise, it was found that commercial strains of Dekkera / Brettanomyces produce high amounts of ethyl esters, which affect the sensory profile, contributing to an overall fruity or floral character. The use of B. bruxellensis as a pure brewing strain, generally, lead to beers containing a large variety of esters, such as ethyl acetate, ethyl lactate, ethyl caproate, and ethyl caprylate. These compounds are desirable; if present in moderate levels, they help increase the flavor complexity of beers, whereas high amounts affect negatively beverage aroma, conferring undesirable, solvent-like buttery and medicinal notes [30]. Otherwise, most authors reported very low quantities of isoamyl acetate, which could be explained by the ability of $B$. bruxellensis to break down this aroma compound, which is highly desirable in wheat beer [31].

Another interesting feature of Dekkera/Brettanomyces is the production of $\beta$-glucosidase, an enzyme responsible for the hydrolysis of glycosides, commonly found in plants, flowers, and fruits, but present also in hops and in the wood of barrels employed for maturation. The enzymatic hydrolysis of glycosides releases sugar molecules, further metabolized, and the aglycone, which can express aromatic activity, representing a poorly explored methodology to improve the aromatic potential of beers. In fact, this could increase or modify the hop aroma, because many of the released monoterpenes, such as linalool (imparting citrus, floral, and aniseed flavours) and methyl salicylate (imparting wintergreen, mint, and spice flavours) are the key aroma substances from hops. D. bruxellensis strains possessing this enzymatic activity might be a good option for fermentations in pure culture or in co-culture with S. cerevisiae [32].

Besides Dekkera/Brettanomyces, which are actually the most frequent non-Saccharomyces yeasts found in brewing, other genera and species can be found during beer production. Among non-conventional yeasts, Wickerhamomyces anomalus and Torulaspora delbrueckii are considered as the most important for this process, in consequence of the production of low amounts of undesirable aromatic compounds, resistance to unfavorable environmental conditions, and recurrent presence in food and beverages. Wickerhamomyces anomalus (Pichia anomala) is a good producer of ethyl propanoate, phenyl ethanol, 2-phenylethyl acetate, and especially ethyl acetate [33]. Such compound is metabolically important in consequence of its antifungal activity. As regards the sensorial influence, this compound affects the taste and flavor profile of the beer, lending an interesting fruity or an unpleasant solvent-like character, depending on the concentration values. Some studies suggest an apparent inability of this species to metabolize maltose [34], whereas other research shows that some wild $W$. anomalus strains are able to use this sugar and to grow even better than other commercial brewing yeasts [35]. In consequence of these findings, W. anomalus stands as a good candidate in sequential or co-inoculated fermentations with other yeasts, also in consequence of its inhibitory action against some microorganisms [33,34].

Torulaspora delbrueckii, a common contaminant in the brewing environment and suggested as a potential brewing yeast firstly by King and Dickinson [36], has been shown to be able to produce high levels of amyl alcohol (fruity flavours) [31] and is often associated with wheat beer, a style typically associated with pronounced fruit notes. This yeast species has the additional advantage of being resistant to the various stresses encountered during brewing, although different strains exhibited different abilities to ferment wort sugars, and this characteristic may explain the variable performance 
observed in different studies [31,37,38]. Tataridis et al. [37] tested T. delbrueckii as a yeast for producing German wheat beer, in comparison to a top-fermenting $S$. cerevisiae strain. The beer produced contained high ester content, with aromas of rose, bubblegum, and banana, and was preferred by most panellists over the control beer (obtained by top-fermenting yeast). In a study aimed at screening 28 strains of T. delbrueckii for their possible use in beer wort fermentation [38], the final beers obtained were described by sensorial analyses as fruity and citric with a full body, demonstrating the suitability of the tested T. delbrueckii strains to be used for producing beers with pleasant and aromatic taste. Furthermore, the finished beers were characterized by a low real attenuation (37\%) and, consequently, low ethanol concentration $(2.66 \% v / v)$, indicating that $T$. delbrueckii could be used also to produce low-alcohol beers. Similar results were found by Michel et al. [39], which tested 10 T. delbrueckii strains from different habitats and found that two strains can be suitable for producing low-alcohol beer, owing to their inability to ferment maltose and maltotriose, but still produced good flavor. However, these authors found also one strain able to ferment the beer wort to an ethanol concentration of $4 \% v / v$ with a desirable fruity and floral aroma, in consequence of production of high amounts of 2-phenylethanol $(23.7 \mathrm{mg} / \mathrm{L})$ and amyl alcohols $(64.83 \mathrm{mg} / \mathrm{L})$. All these results might indicate that the fermentation performance of $T$. delbrueckii strongly depends on the strain. The overall speed of fermentation seems to be slower than that of usual S. cerevisiae brewing strains; however, this species ferments both high and medium original gravity worts, with a high production of higher alcohols and esters [37,39]. The ethanol content of final beers varied from 0.8 to $4 \%(v / v)$, as some strains will not ferment all wort sugars [38,39]. As most studies described an overall fruity flavour in beers obtained by addition of $T$. delbrueckii, some strains could be suitable for potential use in brewing.

In a study aimed at evaluating 17 non-conventional yeasts for the use as starter cultures in sequential beer fermentations with S. cerevisiae [40], P. kluyverii used as single starter culture produced isoamyl acetate and ethyl acetate in very high amounts, while high levels of ethyl acetate and low levels of isoamyl acetate were produced by P. anomala and P. kudriavzevii. When P. kluyverii was used in sequential fermentation with $S$. cerevisiae, inoculated 2 days after $P$. kluyverii with aim of completing the high-gravity beer fermentation, the total level of isoamyl acetate was much lower than expected. In order to use P. kluyverii as starter cultures for the production of beer with highly attractive aromatic characteristics, it will be necessary to optimize the process conditions and/or select the $S$. cerevisiae strains most suitable for the second inoculation.

Some authors [41] proposed the use of Lachancea thermotoleransas pure culture in primary fermentation. As this species is able to produce lactic acid, which affects beer flavour and mouthfeel, they proposed the use of selected strains producing high levels of this compound for the production of sour beer as alternative to the addition of lactic acid bacteria.

\subsection{Non-Conventional Yeasts for Low-Alcohol and Non-Alcoholic Beers}

Among customer demand for more diversity in the beer market, request for low-alcohol (0.5-1.2\% $v / v)$ and non-alcoholic beers $(<0.5 \% v / v)$ beers is constantly increasing. Production of low/no alcohol beers is typically performed by technological approaches, based on either physical removal of alcohol from the beer or an arrested fermentation with the normal production yeast, but in both cases aroma compounds are low or absent due to their evaporation with the alcohol fraction in the former case or no formation in the latter case. The use of yeasts with limited abilities to utilise wort sugars, i.e., maltose-negative yeasts, but that produce typical concentrations of aroma compounds, is a useful alternative to produce low-alcohol beers that still retain some of the aromatic complexity of standard beers. Such yeasts will also reduce wort aldehydes, thereby removing the "worty" taste that is often found in low-alcohol beers produced by arrested fermentation [42]. Different non-Saccharomyces species can be used for these productions. A strain of Saccharomycodes ludwigii has been used commercially for this purpose for many years; it is a good example of the novel use of non-Saccharomyces yeasts in the brewing industry. This species usually shows low performance in fermenting maltose and maltotriose from wort, whereas it forms low concentrations of alcohol by fermenting glucose, fructose, and sucrose. 
This yeast can produce alcohol-free beers with rich flavour profiles owing to its aroma production (mainly esters and higher alcohols). However, as shown by De Francesco et al. [43], the production of esters, as well as the ethanol content of the final beer, is strain-dependent.

Other species considered for these beers include Scheffersomyces shehatae (formerly Candida shehatae) [44], Wickerhamomyces anomalus (formerly Pichia anomala) [34], P. kluyveri [45], and Zygosaccharomyces rouxii [43].

Pichia kluyveri has recently been discovered for producing low-alcohol or alcohol-free beers owing to its limited ability to ferment glucose whilst significantly changing hop compounds into positive flavour compounds [45]. This species produces average levels of esters and high quantities of higher alcohols [46]. The formation of flavour-active compounds, such as average levels of esters and high quantities of higher alcohols, and fast fermentation ability of this species might indicate a brewing potential for novel alcohol-free beer, although to date the commercial use of this strain has not been implemented.

Z. rouxii is considered suitable for producing fermented beverages with low-alcohol content because of its total or partial inability to ferment maltose. As regards this species, different results regarding ethanol production, flavour, and off-flavour formation were reported. Some authors, such as Mortazavian et al. [47], report very low ethanol contents, whereas Sohrabvandi et al. [48] and De Francesco et al. [43] found Z. rouxii to be unsuitable for alcohol-free beer production owing to the high alcohol concentrations in the final beers. Furthermore, De Francesco et al. [43] found a high quantity of esters produced by some of the investigated strains; they also reported diacetyl and 2,3-pentanedione contents that were much higher than the typical taste thresholds.

\subsection{Non-Conventional Yeasts for Light Beers}

Low calorie beers have accounted for a growing market segment, due to obesity problems, especially in Western populations. These beers can be obtained by alternative production methods, addressed mainly to carbohydrates reduction in the final product. A feasible method is the "dilution" of wort carbohydrates, which unfortunately leads to poorly structured and low-flavor expressiveness beers. Another approach is the higher conversion of wort sugars during mashing, which determines a high attenuation level in fermentation, thus lowering the sugar content in the final product. Non-conventional strains with amylase activity can be applied to lower the amount of residual sugars in beer. S. cerevisiae var. diastaticus, formerly known as S. diastaticus, contains three genes (STA1, STA2, and STA3) encoding glucoamylase, an enzyme that catalyses the digestion of dextrins [49]. However, these strains additionally produce strong phenolic off-flavors, limiting their use in beer fermentations. Alternatively, dextrin-degrading non-Saccharomyces species, such as B. bruxellensis, responsible for the superattenuation in Lambic beers by expressing $\alpha$-glucosidase, could be used to drive fermentations in order to obtain highly attenuated beverages. Dekkera/Brettanomyces yeasts are able to metabolize a wide range of carbon sources, including dextrins. These compounds are the main components of the residual sugars in beers fermented by $S$. cerevisiae and can be degraded by $\beta$-glucosidase, an enzyme, commonly produced by Dekkera/Brettanomyces, which is able to degrade those complex molecules into simple sugars and can be readily assimilated, resulting in a "super-attenuated" beer. However, the presence of more fermentable sugars in the wort determines higher level of alcohol in the final products. Since ethanol has a higher energy value in comparison to carbohydrates, the production of low calorie beers requires further removal of part of the alcohol.

\section{Concluding Remarks}

Nowadays, there is increasing customer demand for diversity in beer styles, thus stimulating the search for new approaches, such as the use of alternative yeasts. In this context, an improved understanding of non-conventional yeasts can allow for the selection of strains possessing appropriate traits for particular processes. Non-conventional brewing strains provide alternative metabolic routes for substrate utilization and product formation, such as species possessing useful, and sometimes 
uncommon, metabolic features that are potentially interesting for the production of new beer styles. They produce various volatile compounds affecting the aroma profile of beer and could satisfy consumer demand, providing additional all-natural flavor variants to improve the taste and sensory perception of beers. Moreover, nowadays consumers, in addition to seeking more diversity in the types of beer, are also more aware of their health and increasingly demand low-alcohol and non-alcoholic and light beers.

In conclusion, the use of new brewing yeasts, in addition to alternative raw materials, represents an innovative approach for producing specialty and original beers.

Author Contributions: A.C. and P.R. conceived the idea and outline of the review, R.R. and G.S. contributed to the graphical elaboration of data. All authors contributed to writing specific sections and approved the final version of the manuscript.

Conflicts of Interest: The authors declare no conflict of interest.

\section{References}

1. Steensels, J.; Verstrepen, K.J. Taming wild yeast: Potential of conventional and nonconventional yeasts in industrial fermentations. Ann. Rev. Microbiol. 2014, 68, 61-80. [CrossRef] [PubMed]

2. Bokulich, N.A.; Bamforth, C.W.; Mills, D.A. Brewhouse-resident microbiota are responsible for multi-stage fermentation of American coolship ale. PLoS ONE 2012, 7, e35507. [CrossRef] [PubMed]

3. Martens, H.; Dawoud, E.; Verachtert, H. Synthesis of aroma compounds by wort enterobacteria during the first stage of lambic fermentation. J. Inst. Brew. 1992, 98, 421-425. [CrossRef]

4. Legras, J.-L.; Merdinoglu, D.; Cornuet, J.-M.; Karst, F. Bread, beer and wine: Saccharomyces cerevisiae diversity reflects human history. Mol. Ecol. 2007, 16, 2091-2102. [CrossRef] [PubMed]

5. Gallone, B.; Steensels, J.; Prahl, T.; Soriaga, L.; Saels, V.; Herrera-Malaver, B.; Merlevede, A.; Roncoroni, M.; Voordeckers, K.; Miraglia, L.; et al. Domestication and divergence of Saccharomyces cerevisiae beer yeasts. Cell 2016, 166, 1397-1410.e16. [CrossRef] [PubMed]

6. Gonçalves, M.; Pontes, A.; Almeida, P.; Barbosa, R.; Serra, M.; Libkind, D.; Hutzler, M.; Gonçalves, P.; Sampaio, J.P. Distinct domestication trajectories in top-fermenting beer yeasts and wine yeasts. Curr. Biol. 2016, 26, 2750-2761. [CrossRef] [PubMed]

7. González, S.S.; Barrio, E.; Querol, A. Molecular characterization of new natural hybrids of Saccharomyces cerevisiae and S. kudriavzevii in brewing. Appl. Environ. Microbiol. 2008, 74, 2314-2320. [CrossRef] [PubMed]

8. Gibson, B.; Geertman, J.-M.A.; Hittinger, C.T.; Krogerus, K.; Libkind, D.; Louis, E.J.; Magalhães, F.; Sampaio, J.P. New yeasts-new brews: Modern approaches to brewing yeast design and development. FEMS Yeast Res. 2017, 17. [CrossRef] [PubMed]

9. Bond, U.; Neal, C.; Donnelly, D.; James, T.C. Aneuploidy and copy number breakpoints in the genome of lager yeasts mapped by microarray hybridisation. Curr. Genet. 2004, 45, 360-370. [CrossRef] [PubMed]

10. Bond, U. The genomes of lager yeasts. Adv. Appl. Microbiol 2009, 69, 159-182. [CrossRef] [PubMed]

11. Dunn, B.; Sherlock, G. Reconstruction of the genome origins and evolution of the hybrid lager yeast Saccharomyces pastorianus. Genome Res. 2008, 18, 1610-1623. [CrossRef] [PubMed]

12. Nakao, Y.; Kanamori, T.; Itoh, T.; Kodama, Y.; Rainieri, S.; Nakamura, N.; Shimonaga, T.; Hattori, M.; Ashikari, T. Genome sequence of the lager brewing yeast, an interspecies hybrid. DNA Res. 2009, 16, 115-129. [CrossRef] [PubMed]

13. Libkind, D.; Hittinger, C.T.; Valerio, E.; Goncalves, C.; Dover, J.; Johnston, M.; Goncalves, P.; Sampaio, J.P. Microbe domestication and the identification of the wild genetic stock of lager-brewing yeast. Proc. Natl. Acad. Sci. USA 2011, 108, 14539-14544. [CrossRef] [PubMed]

14. Gibson, B.R.; Storgards, E.; Krogerus, K.; Vidgren, V. Comparative physiology and fermentation performance of Saaz and Frohberg lager yeast strains and the parental species Saccharomyces eubayanus. Yeast 2013, 30, 255-266. [CrossRef] [PubMed]

15. Krogerus, K.; Magalhaes, F.; Vidgren, V.; Gibson, B. Novel brewing yeast hybrids: Creation and application. Appl. Microbiol. Biotechnol. 2017, 101, 65-78. [CrossRef] [PubMed]

16. Monerawela, C.; Bond, U. Brewing up a storm: The genomes of lager yeasts and how they evolved. Biotechnol. Adv. 2017, 35, 512-519. [CrossRef] [PubMed] 
17. Magalhaes, F.; Vidgren, V.; Ruohonen, L.; Gibson, B. Maltose and maltotriose utilisation by group I strains of the hybrid lager yeast Saccharomyces pastorianus. FEMS Yeast Res. 2016, 16. [CrossRef] [PubMed]

18. Rainieri, S.; Kodama, Y.; Kaneko, Y.; Mikata, K.; Nakao, Y.; Ashikari, T. Pure and mixed genetic lines of Saccharomyces bayanus and Saccharomyces pastorianus and their contribution to the lager brewing strain genome. Appl. Environ. Microbiol. 2006, 72, 3968-3974. [CrossRef] [PubMed]

19. Saerens, S.M.G.; Duong, C.T.; Nevoigt, E. Genetic improvement of brewer's yeast: Current state, perspectives and limits. Appl. Microbiol. Biotechnol. 2010, 86, 1195-1212. [CrossRef] [PubMed]

20. Hewitt, S.K.; Donaldson, I.J.; Lovell, S.C.; Delneri, D. Sequencing and characterization of rearrangements in three $S$. pastorianus strains reveals the presence of chimeric genes and gives evidence of breakpoint reuse. PLoS ONE 2014, 9, e92203. [CrossRef] [PubMed]

21. Okuno, M.; Kajitani, R.; Ryusui, R.; Morimoto, H.; Kodama, Y.; Itoh, T. Next-generation sequencing analysis of lager brewing yeast strains reveals the evolutionary history of interspecies hybridization. DNA Res. 2016, 23, 67-80. [CrossRef] [PubMed]

22. Walther, A.; Hesselbart, A.; Wendland, J. Genome sequence of Saccharomyces carlsbergensis, the world's first pure culture lager yeast. G3 Genes Genomes Genet. 2014, 4, 783-793. [CrossRef] [PubMed]

23. Karabín, M.; Jelínek, L.; Kotrba, P.; Cejnar, R.; Dostálek, P. Enhancing the performance of brewing yeasts. Biotechnol. Adv. 2018. [CrossRef] [PubMed]

24. Marongiu, A.; Zara, G.; Legras, J.L.; Del Caro, A.; Mascia, I.; Fadda, C.; Budroni, M. Novel starters for old processes: Use of Saccharomyces cerevisiae strains isolated from artisanal sourdough for craft beer production at a brewery scale. J. Ind. Microbiol. Biotechnol. 2015, 42, 85-92. [CrossRef] [PubMed]

25. Budroni, M.; Zara, G.; Ciani, M.; Comitini, F. Saccharomyces and non-Saccharomyces starter yeast. In Brewing Technology; Kanauchi, M., Ed.; INTECH: Rijeka, Croatia, 2017; pp. 81-100. [CrossRef]

26. Alves-Araújo, C.; Pacheco, A.; Almeida, M.J.; Spencer-Martins, I.; Leão, C.; Sousa, M.J. Sugar utilization patterns and respiro-fermentative metabolism in the baker's yeast Torulaspora delbrueckii. Microbiology 2007, 153, 898-904. [CrossRef] [PubMed]

27. Aguilar-Uscanga, M.G.; Délia, M.L.; Strehaiano, P. Brettanomyces bruxellensis: Effect of oxygen on growth and acetic acid production. Appl. Microbiol. Biotechnol. 2003, 61, 157-162. [CrossRef] [PubMed]

28. Ricci, A.; Allende, A.; Bolton, D.; Chemaly, M.; Davies, R.; Girones, R.; Herman, L.; Koutsoumanis, K.; Lindqvist, R.; Nørrung, B.; et al. Scientific opinion on the update of the list of QPS-recommended biological agents intentionally added to food or fee as notified to EFSA. EFSA J. 2017. [CrossRef]

29. Vanderhaegen, B.; Neven, H.; Coghe, S.; Verstrepen, K.J.; Derdelinckx, G.; Verachtert, H. Bioflavoring and beer refermentation. Appl. Microbiol. Biotechnol. 2003, 62, 140-150. [CrossRef] [PubMed]

30. Cortés-Diéguez, S.; Rodriguez-Solana, R.; Domínguez, J.M.; Díaz, E. Impact odorants and sensory profile of young red wines from four Galician (NW of Spain) traditional cultivars. J. Inst. Brew. 2015, 12, 628-635. [CrossRef]

31. Michel, M.; Meier-Dörnberg, T.; Jacob, F.; Methner, F.-J.; Wagner, R.S.; Hutzler, M. Review: Pure non-Saccharomyces starter cultures for beer fermentation with a focus on secondary metabolites and practical applications. J. Inst. Brew. 2016, 122, 569-587. [CrossRef]

32. Basso, R.F.; Alcarde, A.R.; Portugal, C.B. Could non-Saccharomyces yeasts contribute on innovative brewing fermentations? Food Res. Int. 2016, 86, 112-120. [CrossRef]

33. Passoth, V.; Fredlund, E.; Druvefors, U.Ä.; Schnürer, J. Biotechnology, physiology and genetics of the yeast Pichia anomala. FEMS Yeast Res. 2006, 6, 3-13. [CrossRef] [PubMed]

34. Walker, G. Pichia anomala: Cell physiology and biotechnology relative to other yeasts. Antonie van Leeuwenhoek 2011, 99, 25-34. [CrossRef] [PubMed]

35. Lee, Y.-J.; Choi, Y.-R.; Lee, S.-Y.; Park, J.-T.; Shim, J.-H.; Park, K.-H.; Kim, J.-W. Screening wild yeast strains for alcohol fermentation from various fruits. Mycobiology 2011, 39, 33-39. [CrossRef] [PubMed]

36. King, A.; Dickinson, J.R. Biotransformation of monoterpene alcohols by Saccharomyces cerevisiae, Torulaspora delbrueckii and Kluvveromyces lactis. Yeast 2000, 16, 499-506. [CrossRef]

37. Tataridis, P.; Kanelis, A.; Logotetis, S.; Nerancis, E. Use of non-Saccharomyces Torulaspora delbrueckii yeast strains in winemaking and brewing. J. Nat. Sci. 2013, 124, 415-426. [CrossRef]

38. Canonico, L.; Agarbati, A.; Comitini, F.; Ciani, M. Torulaspora delbrueckii in the brewing process: A new approach to enhance bioflavour and to reduce ethanol content. Food Microbiol. 2016, 56, 45-51. [CrossRef] [PubMed] 
39. Michel, M.; Kopecká, J.; Meier-Dörnberg, T.; Zarnkow, M.; Jacob, F.; Hutzler, M. Screening for new brewing yeasts in the non-Saccharomyces sector with Torulaspora delbrueckii as model. Yeast 2016, 33, 129-144. [CrossRef] [PubMed]

40. Holt, S.; Mukherjee, V.; Lievens, B.; Verstrepen, K.J.; Thevelein, J.M. Bioflavoring by non-conventional yeasts in sequential beer fermentations. Food Microbiol. 2018, 72, 55-66. [CrossRef] [PubMed]

41. Domizio, P.; House, J.F.; Joseph, C.M.L.; Bisson, L.F.; Bamforth, C.W. Lachancea thermotolerans as an alternative yeast for the production of beer. J. Inst. Brew. 2016, 122, 599-604. [CrossRef]

42. Saison, D.; De Schutter, D.P.; Vanbeneden, N.; Daenen, L.; Delvaux, F.; Delvaux, F.R. Decrease of aged beer aroma by the reducing activity of brewing yeast. J. Agric. Food Chem. 2010, 58, 3107-3115. [CrossRef] [PubMed]

43. De Francesco, G.; Turchetti, B.; Sileoni, V.; Marconi, O.; Perretti, G. Screening of new strains of Saccharomycodes ludwigii and Zygosaccharomyces rouxii to produce low-alcohol beer. J. Inst. Brew. 2015, 121, 113-121. [CrossRef]

44. Li, H.; Liu, Y.; Zhang, W. Method for Preparing Non-Alcoholic Beer by Candida shehatae. Patent No. CN102220198B, 6 February 2013.

45. Saerens, S.; Swiegers, J.H. Production of Low-Alcohol or Alcohol-Free Beer with Pichia kluyveri Yeast Strains. Patent No. WO2014135673A2, 12 September 2014.

46. Amaya-Delgado, L.; Herrera-López, E.J.; Arrizon, J.; Arellano-Plaza, M.; Gschaedler, A. Performance evaluation of Pichia kluyveri, Kluyveromyces marxianus and Saccharomyces cerevisiae in industrial tequila fermentation. World J. Microbiol. Biotechnol. 2013, 29, 875-881. [CrossRef] [PubMed]

47. Mortazavian, A.; Razavi, S.; Mousavi, S.; Malganji, S.; Sohrabvandi, S. The effect of Saccharomyces strain and fermentation conditions on quality parameters of non-alcoholic beer. J. Paramed. Sci. 2014, 5, 21-26.

48. Sohrabvandi, S.; Razavi, S.H.; Mousavi, S.M.; Mortazavian, A.M. Characteristics of different brewer's yeast strains used for nonalcoholic beverage fermentation in media containing different fermentable sugars. Int. J. Biotechnol. 2010, 8, 178-185.

49. Ogata, T.; Iwashita, Y.; Kawada, T. Construction of a brewing yeast expressing the glucoamylase gene STA1 by mating. J. Inst. Brew. 2017, 123, 66-69. [CrossRef]

(C) 2018 by the authors. Licensee MDPI, Basel, Switzerland. This article is an open access article distributed under the terms and conditions of the Creative Commons Attribution (CC BY) license (http:/ / creativecommons.org/licenses/by/4.0/). 